\title{
IDENTIDAD A DOS VELOCIDADES Morfología, estructura y sociedad en dos zonas urbanas de la ciudad de Torreón
}

\author{
Angela Mourey López Negrete \\ Universidad Politécnica de Catalunya \\ Estanislau Roca Blanch y Miquel Martí Casanovas, Doctores \\ angela.mourey@gmail.com
}

\section{RESUMEN}

El estudio genera un análisis sobre dos ejes de centralidad en Torreón, México con la intención de poner en valor la identidad de la ciudad. Uno de ellos será el eje de la centralidad tradicional y el otro el eje de la centralidad periférica Raúl López Sánchez. El parámetro diferencial evidente entre ellos es la velocidad de flujo del tráfico rodado.

La morfología y la estructura urbana en ambas zonas son el sustento de la posible generación de manifestaciones de identidad. Utilizando el dibujo como herramienta de análisis, se verifica la hipótesis anterior. Se obtiene que ambas zonas presentan condiciones urbanas particulares y distintas que conducen a manifestaciones sociales de identidad clasificadas en las siguientes categorías: imagen, tradición, cultura, festividad, arte y edificación patrimonial.

Palabras clave: Identidad, forma, estructura y velocidad

\section{ABSTRACT}

This study generates an analysis of two urban axis at Torreon, Mexico with the intention of evaluating the city's identity. This two axis of urban centralization are the traditional and the peripheral Raul Lopez Sanchez centralities. The velocity at which motorized vehicles travel is the most evident differentiation between this two axes.

The morphology and structure of this two axis create a base for the possible generation of identity manifestations. The verification of the previous hypothesis is done by the use of the drawing as a tool for analysis. This analysis obtains the conclusion that both urban axis have particular and different conditions that conduce to the social manifestations which are classified on image, tradition, culture, festivity, art and building heritage.

Key words: Identity, morphology, structure and velocity. 


\section{PRESENTACIÓN}

\subsection{Objetivo}

1. Estudiar cómo se manifiesta la identidad urbana en las áreas centrales y periféricas de la ciudad en relación a la morfología y la estructura urbana.

2. Reflexionar sobre las condiciones morfológicas y estructurales que permiten que se generen manifestaciones de identidad.

\subsection{Hipótesis}

1. La velocidad a la cual circulan las personas en cada una de estas áreas de centralidad es muy distinta (más peatonal en la ciudad histórica y más veloz en la periférica) e incide en la formas de identidad de cada una de ellas.

2. La morfología y la estructura urbana en los ejes de la centralidad tradicional y periférica es distinta y por esta razón permiten distintas manifestaciones de identidad.

3. Las dinámicas de población en Torreón producen un doble efecto en su sistema de centralidades: un deterioro del centro tradicional y la aparición de nuevas centralidades más periféricas.

4. El centro histórico basa su identidad en el potencial de una trama urbana compacta en la que se conserva un tejido comercial de grano pequeño en la que se mantienen costumbres y manifestaciones culturales.

5. El periférico y sus centralidades por polarización generan con dificultad, nuevas formas de identidad a partir de usos genéricos como los centros comerciales y edificios de bajo valor patrimonial.

\subsection{Metodología}

Estudiar la identidad del territorio contrastando dos zonas distintas, una centralidad histórica y una centralidad periférica, en Torreón Coahuila, México. Esta identidad se analiza en base a dibujos de morfología y estructura urbana lo cual permite sacar conclusiones sobre el sustento que ambas permiten para la aparición de manifestaciones de identidad clasificadas en las siguientes categorías: la imagen urbana, la tradición, la cultura, la festividad, el arte y las edificaciones patrimoniales.

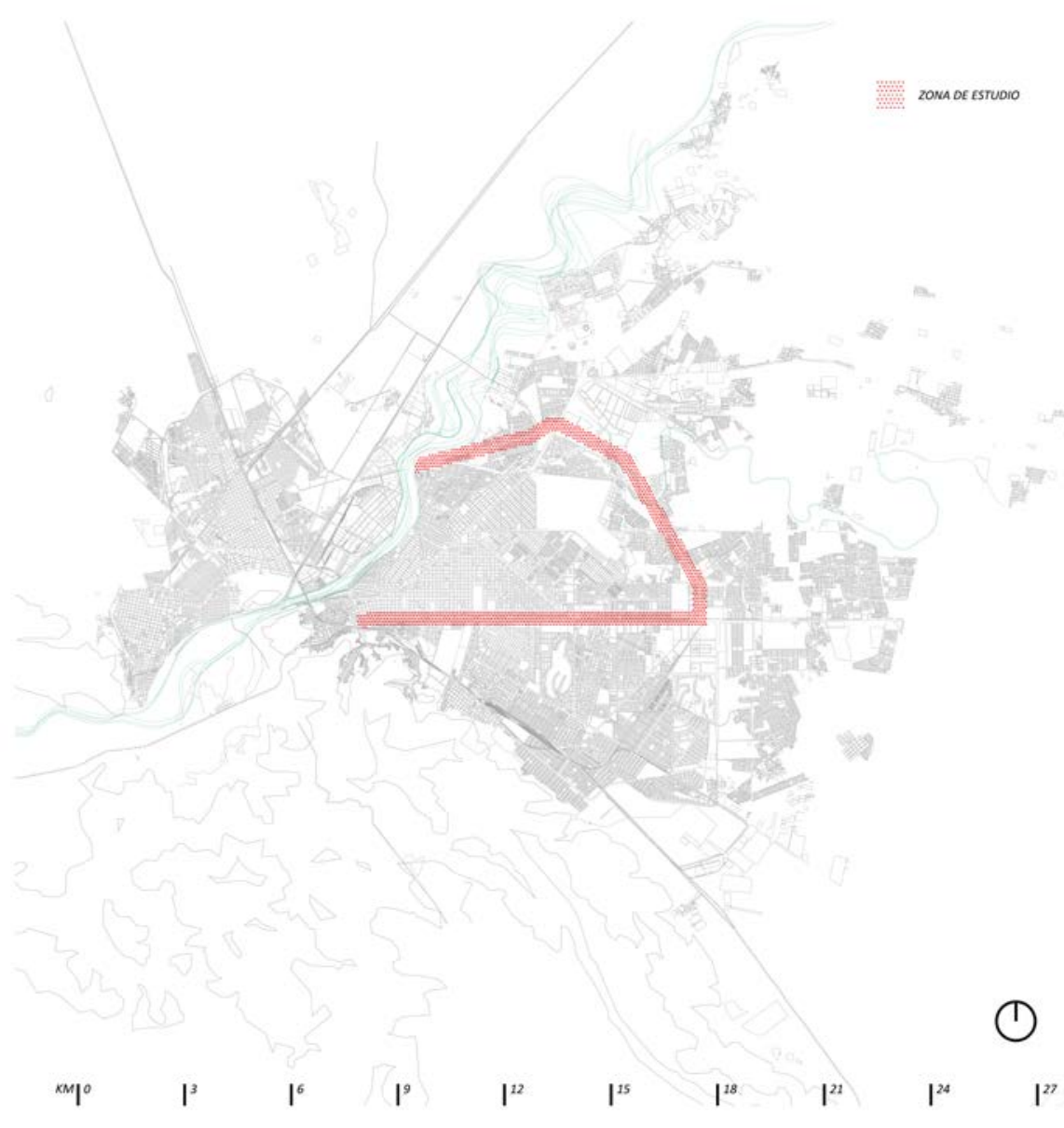

Fig. 1 Localización de área de estudio. Elaboración propia a partir de cartografía urbana 

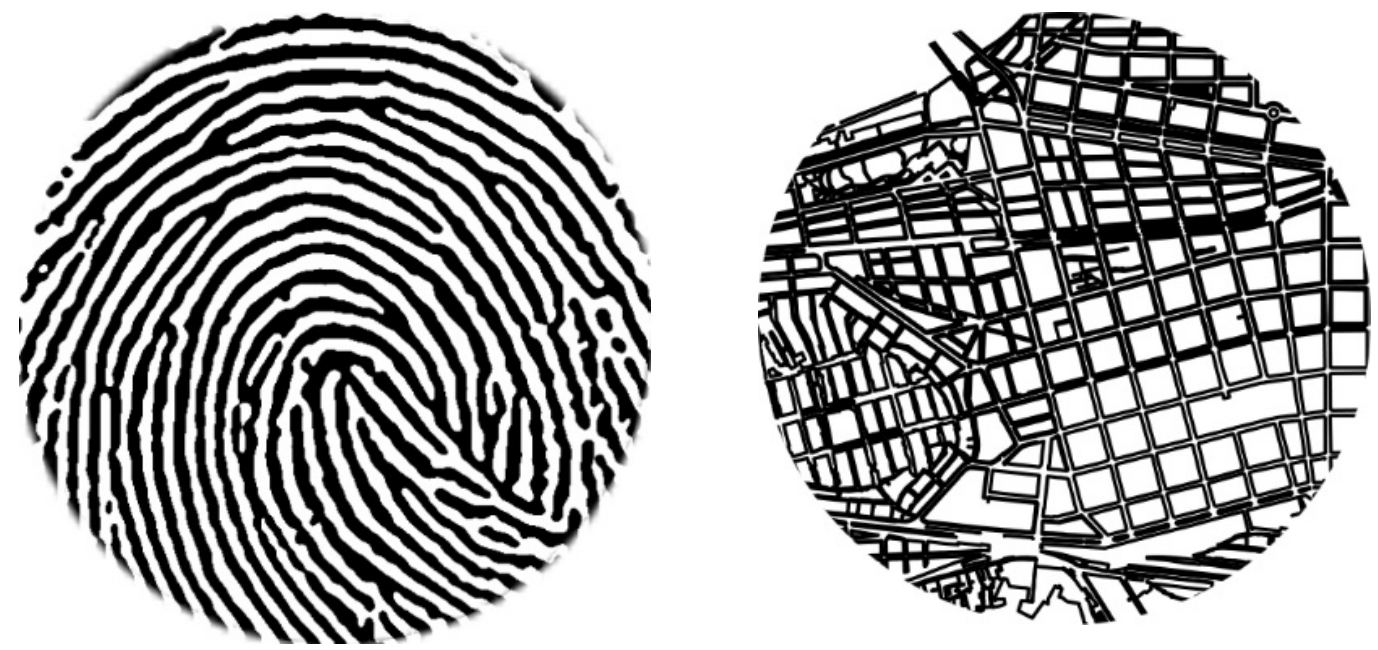

Fig. 2 Imagen gráfica conceptual. Elaboración propia a partir de cartografía urbana e imagen gráfica

Según el diccionario de la Real Academia Española la palabra identidad proviene de latín tardío "identitas" y este de la entrada "ídem" que significa "lo mismo".

Su significado se define como:

1. Un conjunto de rasgos propios de un individuo o de una colectividad que los caracterizan frente a los demás.

2. Conciencia que una persona tiene de ser ella misma distinta a las demás.

3. Hecho de ser alguien o algo el mismo que se supone o se busca.

A partir de esta definición etimológica se puede generar una conceptualización variable cuando se enfatiza en el ámbito urbano y social. Por esta razón, es necesario explicar la conceptualización de este modesto trabajo cuando no se ha especializado una vida en ello. Por medio de interesantes reflexiones teóricas podemos interpretar el significado de la palabra identidad. Planteo mi propia definición en base a los especialistas que a mi conocimiento han utilizado el término. Dicho acto lo realizo con temor a omitir des intencionadamente a intelectuales en el área.

\subsection{Citas sobre identidad}

1961

"La suma de todos estos contactos casuales y públicos en un nivel local, la mayoría de ellos fortuitos, la mayoría propiciados por recados que la gente hace para sí misma, no por encargo, es un sentimiento de identidad pública de la gente, una red de respeto público y de confianza, y un recurso en los momentos de necesidad personal o vecinal. La ausencia de esta confianza es un desastre para las calles de una ciudad." (Jacobs p. 72)

"El ocupante de un anónimo inmueble vernáculo en una calle medieval italiana puede lograr su identidad mediante la decoración en la puerta de la calle[...]Pero el habitante de clase media de un suburbio que ocupe una casa no anterior a la guerra, sino una versión menor y perdida en un gran espacio, ha de buscar su identidad mediante el tratamiento simbólico de la forma de la casa, ya sea con elementos estilísticos suministrados por el promotor[...]ya sea a diversos ornamentos simbólicos que aplica después el propietario." (Robert Venturi, Steven Izenour y Denise Scott Brown p.189-190) 

de lo real, en cierto modo no podemos imaginarnos que algo contemporáneo -hecho por nosotros- contribuya a ella. Pero el hecho de que el crecimiento humano sea exponencial implica que el pasado en un cierto punto se volverá demasiado "pequeño" para ser habitado y compartido por aquellos que están vivos. [...] no se puede particularizar lo genérico a través del Genérico. [...] Su identidad es como un mantra." (Koolhas)

1995

"Si un lugar puede definirse como espacio de identidad, relacional e histórico, un espacio que no pueda definirse ni como espacio de identidad ni como relacional ni como histórico, definirá un no lugar... un mundo así prometido a la individualidad solitaria, a lo efímero, al pasaje..." (Augé p.77)

"Las identidades son fuentes de sentido para los propios actores y por ellos mismos son construidas mediante un proceso de individualización. Aunque, cómo sostendré más adelante, las identidades pueden originarse en las instituciones dominantes, sólo se convierten en tales si los actores sociales las interiorizan y construyen su sentido en torno a esta interiorización." (Castells p.29)

"La coherencia de la imagen puede darse de diversas maneras. Puede ser poco en el objeto real lo que resulte ordenado o notable, y pese a esto su imagen mental ha adquirido identidad y organización a través de una larga familiaridad. [...]Por otra parte, un objeto visto por primera vez puede ser identificado y relacionado no porque sea familiar sino porque se ajusta a un cliché ya construido por el observador.[...]se le da el nombre de identidad, no con el sentido de igualdad con otra cosa sino con el significado de individualidad o unicidad." (Lynch, La imagen de la ciudad 15-17)

1999

“...la congregación humana unida por lazos basados en el calor y la autenticidad: una agrupación de individuos, de efectivos reducidos, distinguibles, territorializados, cuyos miembros comparten rasgos, valores e intereses específicos, con una organización singular y funcionalmente autosuficiente, y que aparecen dotados de un cierto sentido de la identidad." (Delgado p.133)

“...la forma urbana -y, por lo tanto, la ordenación del espacio público - es un factor de aglutinamiento social y de creación de identidades..." (Jordi Borja y Zaida Muxi p.5)

"...la existencia de patrones y leyes de ocupación que transforman el territorio, definiendo una lógica formal propia que sintetiza y representa su identidad." (Joaquin Sabaté y Julián Galindo p.22)

“...se da otro tipo de batalla por la identidad centrada en la historia, cultura, estética, mitologías, recuerdos y tradiciones colectivas." (Harvey p.160)

“...pueden detectarse esas nuevas lógicas de localización y esos nuevos artefactos característicos de la nueva etapa del proceso de urbanización metropolitana. Todo ello se presenta frecuentemente, además de como imagen indiscutible de modernidad, como seña de identidad o de pertenencia a un mundo cada vez más homogéneo." (Font p.22)

\subsection{Definición personal}

El concepto identidad en relación al urbanismo es la concepción de una individualidad, unicidad y autenticidad que tiene sentido por medio de los propios ciudadanos. Son ellos quienes la construyen e interiorizan por contactos casuales y públicos que ocurren de manera fortuita y con cierta continuidad en la forma, el espacio y la estructura urbana. A partir de este contacto se manifiestan elementos de identidad reflejados en distintos ámbitos como la historia, la cultura, las festividades, las tradiciones, el arte, los recuerdos y el patrimonio de una sociedad. En contraposición a ello se encuentra la definición de la identidad como un "mantra". Esta definición nace a través de los espacios genéricos que las nuevas urbanizaciones han creado y que aún están en proceso de su definición como identidad. 


\section{LA CIUDAD DE TORREÓN - CONTEXTUALIZACIÓN GENERAL 3.1 El relato}

Torreón es una ciudad que en 2017 cumple 110 años de su fundación. Es una ciudad que se ha formado rápidamente, acojiendo familias de distintas nacionalidades y localidades dentro de la nación. La identidad etnica adoptada en la ciudad es múltiple; se basa en elementos físicos de "poca" antigüedad y en comportamientos sociales con historias, culturas, mitologías, tradiciones y recuerdos de gran variedad.

El territorio tiene una identidad auténtica carente de reconocimiento universal pero con el paso del tiempo se ha manifestado localmente una necesidad por dar valor a ésta identidad. Se han realizado manifestaciones sociales que abogan por la preservación de la historia, la cultura, la tradición, la festividad y el arte de la ciudad. Se genera un proceso de maduración para el reconocimiento identitario de los patrónes, leyes y lógicas de ocupación del territorio que darán valor y preservación a la identidad urbana.

\subsection{El centro tradicional}

La extensión territorial y la movilidad basada principalmente en el vehículo privado han creado centros periféricos que desestiman la centralidad tradicional. Se han generado nuevos espacios y formas urbanas que predisponen una nueva identidad. Las personas se han abandonado las zonas más históricas para desplazarse hacia las nuevas urbanizaciones causando un deterioro de la centralidad tradicional. Empero, la emigración ha sido -aunque no verificada- por la búsqueda de una mayor calidad de vida.

¿Cuál es la identidad que estos nuevos crecimientos urbanos propician? ¿Cómo es que la forma y el espacio urbano promueven la generación o niegan el contacto casual base de una identidad? ¿Serán éstos espacios generadores de una individualidad, unicidad, autenticidad social en los habitantes? ¿Es posible generar una manifestación histórica, cultural, tradicional colectiva en estas nuevas centralidades? ¿Permanecerá la existencia de las formas de identidad en el centro tradicional? ¿Cuáles son las posibilidades del territorio para fomentar la identidad? ¿Estos nuevos crecimientos habrán puesto en valor la identidad tradicional del territorio o se habrá creado una nueva forma de identidad?

"Es la imagen que permite a los ciudadanos identificarse con su pasado y presente como una entidad cultural, política y social. Los espacios privilegiados de los monumentos como marcas en el tejido de la ciudad..." (Castells:1997)

El centro histórico, producto del origen de la ciudad, es la zona donde se ubica la primera estación ferroviaria de intercambio entre la línea central mexicana y la internacional. En la actualidad ese flujo solo funciona para el ámbito industrial. En su tiempo, este acontecimiento impulsó el interés de las personas por asentarse en el territorio, fabricar y comercializar. Los primeros establecimientos comerciales, habitacionales y de equipamiento se fueron desplantando sobre esa centralidad. La diversidad de usos y el aumento en la densidad poblacional creó un espacio mixto y vivo; se proyectó un centro consolidado con espacios de proximidad peatonal que permitieron el contacto entre los elementos urbanos y sus ciudadanos. Estos contactos cotidianos y públicos hicieron del espacio urbano una identidad implícita. En esta joven ciudad se abrió camino a la historia, la cultura, los recuerdos y la tradición. Son aquellas manifestaciones testimonio de la huella de los torreonenses, elementos de identidad que han evolucionado y que aún sobreviven en la memoria colectiva de quienes la habitan.

La especulación inmobiliaria y el incremento poblacional derivaron en la creación de nuevos centros periféricos. La ciudad se convirtió en un modelo poli céntrico con una extensión y una discontinuidad entre lo nuevo y la ciudad histórica. Se terminó así con muchos de los contactos casuales que anteriormente sucedían y se diluyó la vida social entre los edificios. Las nuevas urbanizaciones no han valorado el esfuerzo por construir la ciudad y esa falta de conciencia ha terminado con varios de los inmuebles históricos. Hoy padecemos un déficit en el paisaje urbano tradicional.

Desde el año 2012, una serie de proyectos públicos y privados se han puesto en marcha con la finalidad de reactivar el centro tradicional; pero esas iniciativas parecen una imposición más que un consenso comunitario. La unión y participación ciudadana es necesaria, una sinergia que provoque que las construcciones o remodelaciones en el centro tradicional en base a iniciativas, ya sean privadas o irónicamente públicas, respondan al interés colectivo y dialoguen con la urbanización fundacional. 
Lo que una vez fue una ciudad diversa se ve maniatada por el aumento en la instalación de bares y restaurantes; el uso de suelo se ha monopolizado principalmente al sector terciario. La homogeneidad del uso del suelo y la baja densidad poblacional -como lo refirió Jane Jacobs- va en contra de la diversidad como generador de la vida pública.

El corazón de Torreón, que reside en su centro tradicional aún reclama impulso. Volver la mirada cien años cuando la vivienda en proximidad sumado a los usos cotidianos nos regalaban un espacio integro. Ahora la actividad se resume al ocio, algunas oficinas y a las expresiones de arte que aun sobreviven. La vivienda habitada es prácticamente nula, es necesario otros usos provoquen mayor vida durante el día al espacio urbano. En el mejor escenario robustecer el sistema de transporte público, lo que estrecharía el uso del vehículo privado, deteniendo sus efectos negativos y reactivando la vida en las aceras.

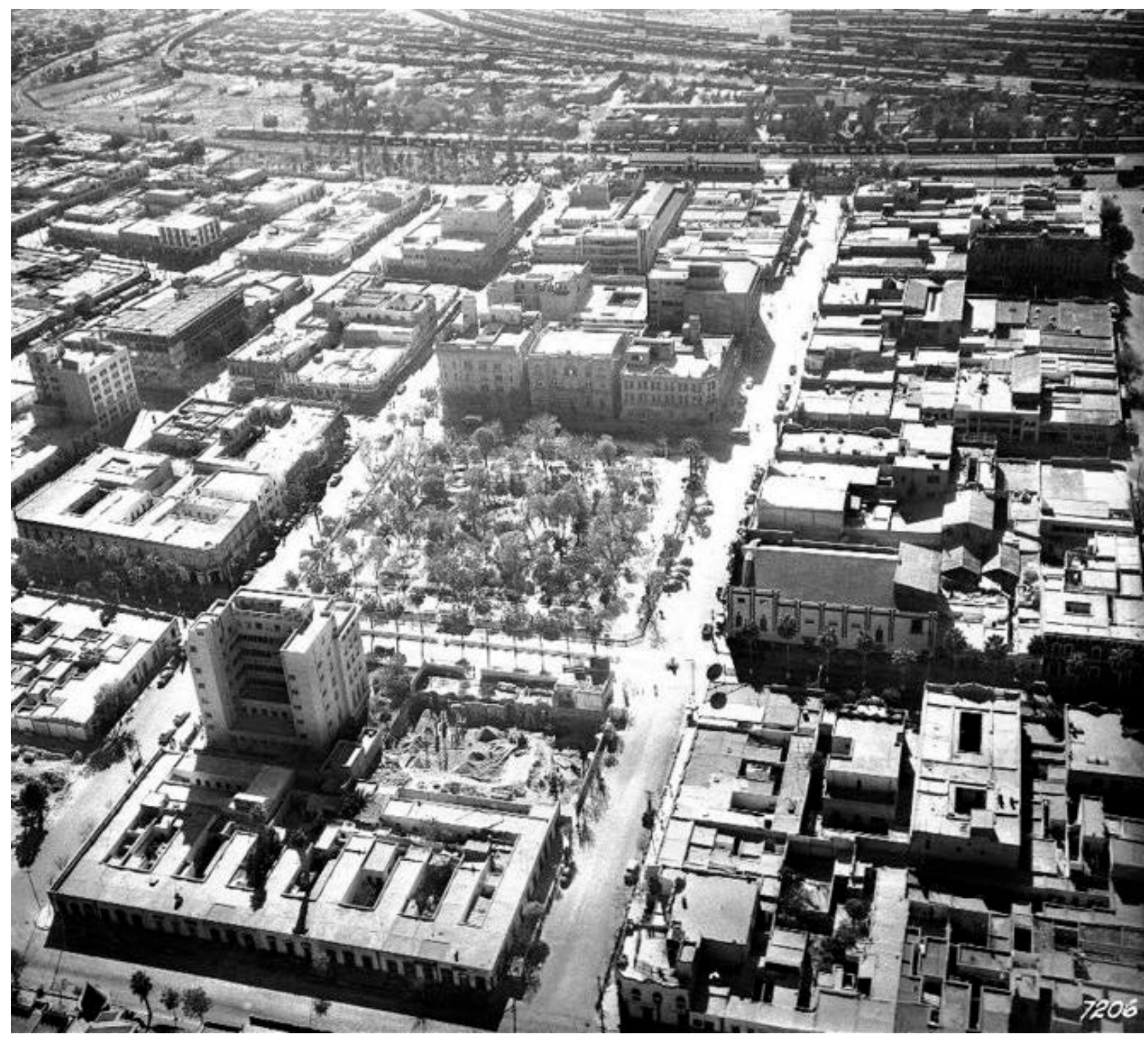

Fig. 3 Vista aérea del centro tradicional. (Archivo Municipal Eduardo Guerra) 


\subsection{El periférico Raúl López Sánchez}

El periférico Raúl López Sánchez se ha convertido en una de las nuevas centralidades. Esta vía ha tomado la importancia de funcionar como un conector entre las distintas municipalidades de la región. Muchos de los nuevos establecimientos se han localizado en esta zona. Esta vía cuenta con un gran tráfico de vehículos conduciendo a alta velocidad y sus elementos edificados son dispersos. Hay menor posibilidad de vinculación entre los ciudadanos y el entorno no genera la casualidad física. La proyección urbana crea una percepción espacial amplia que obliga al habitante a recordar solo los hitos urbanos. Es un salto de escala con identidad impersonal, donde no existe la apropiación del espacio urbano ni las actividades históricas, tradicionales, o culturales.

En el periférico la vivienda pasó a planificarse mediante fraccionamientos residenciales de gran extensión territorial, colocando a los ciudadanos en un constante deseo por vivir bajo el esquema de la ciudad jardín. Aquellos proyectos muchas veces están cerrados en sí mismos con bardas y accesos restringidos, espacios "privados" que no generan ciudad desde la perspectiva de la colectividad. En contraste con las alturas que venían proyectando los edificios del centro histórico, los nuevos fraccionamientos no superan los dos niveles de altura.

A lo largo de la centralidad periférica el uso del suelo se ha convertido en islas de monotonía. En consecuencia, se deberán recorrer distancias aún mayores para llegar, por ejemplo, de una vivienda a un comercio. Si a esto sumamos que la centralidad tiene una carencia de aceras y ciclo vías encontramos que un peatón se encuentra prácticamente imposibilitado para realizar eficientemente su recorrido. Esa estructura urbana es un círculo vicioso, donde la insuficiencia en la movilidad colectiva solo se resuelve con el uso del transporte privado. En síntesis, el gran número de vehículos privados generan una ciudad que además de ser impersonal e individualista, es insostenible.

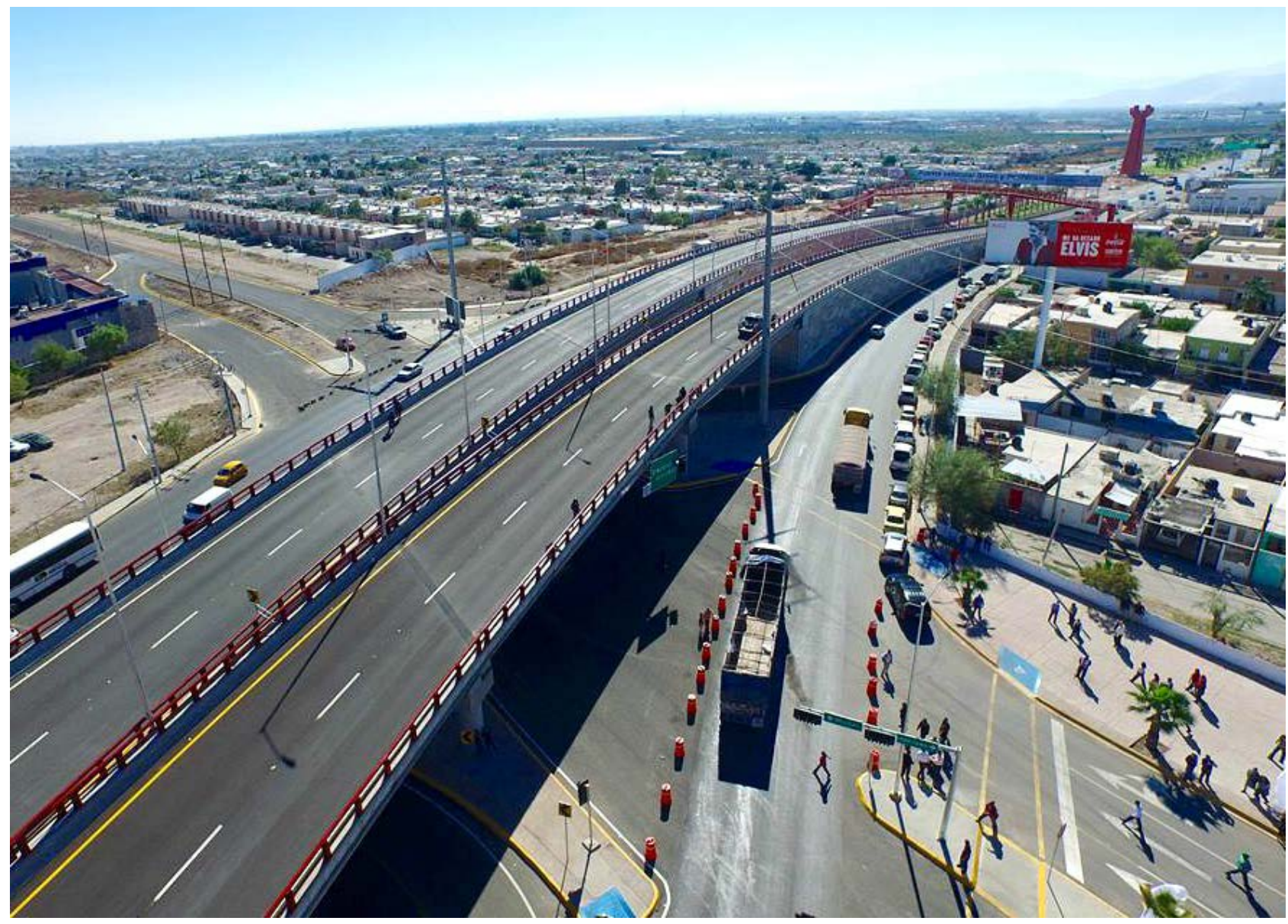

Fig. 4 Imagen Panorámica del periférico Raúl López Sánchez 
Si el objetivo del espacio urbano del periférico consiste en construir la ciudad para propósito futuro podremos estar en lo correcto puesto que aquí la imagen y en consecuencia la identidad se dará de forma distinta al centro tradicional. Cuando se proyecta una nueva urbanización debemos crear, como explica Kevin Lynch, espacios que sean adaptables al futuro con una sensatez y claridad en la imagen. La imagen ambiental tiene tres partes analíticas: identidad, estructura y significado. Haciendo una transposición podemos ser capaces de identificar piezas urbanas que tenga individualidad, unicidad y que además sea emotivo para el observador.

“...mostraremos sensatez si concentramos la atención en la claridad física de la imagen y permitimos que el significado se desarrolle sin nuestra guía directa." (Lynch, La imagen de la ciudad p.18)

La situación que observamos en el periférico donde se privilegia el crecimiento urbano acelerado, corre el riesgo de caer en lo que Rem Koolhas denominaría como la ciudad genérica. Cuando una nueva urbanización se proyecta, toma tiempo incluso décadas que se le otorgue una identidad generada por los ciudadanos. Es un sitio genérico. En estos casos la identidad es un mantra, algo que no precisamente tiene autenticidad. En éste caso la morfología y la estructura urbana deberá ser proyectada como un medio para la posible apropiación del entorno urbano y la consecuente manifestación de identidad.

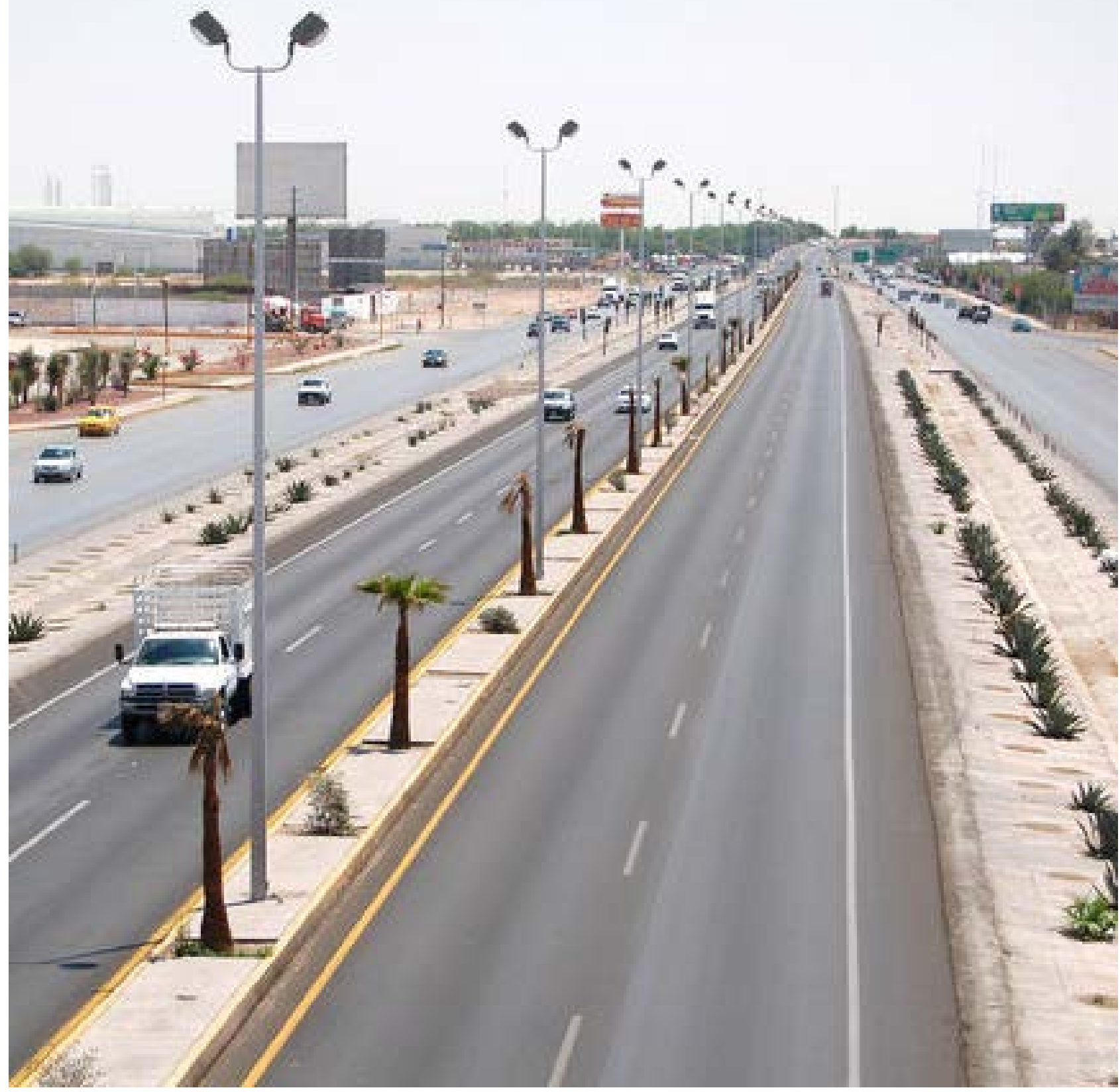

Fig. 5 Vista Periférico Raúl López Sánchez 


\section{LA MORFOLOGÍA URBANA - GENERADOR DE IDENTIDAD EN LA CENTRALIDAD TRADICIONAL Y PERIFÉRICA}

\subsection{Tramas y tejidos urbanos}

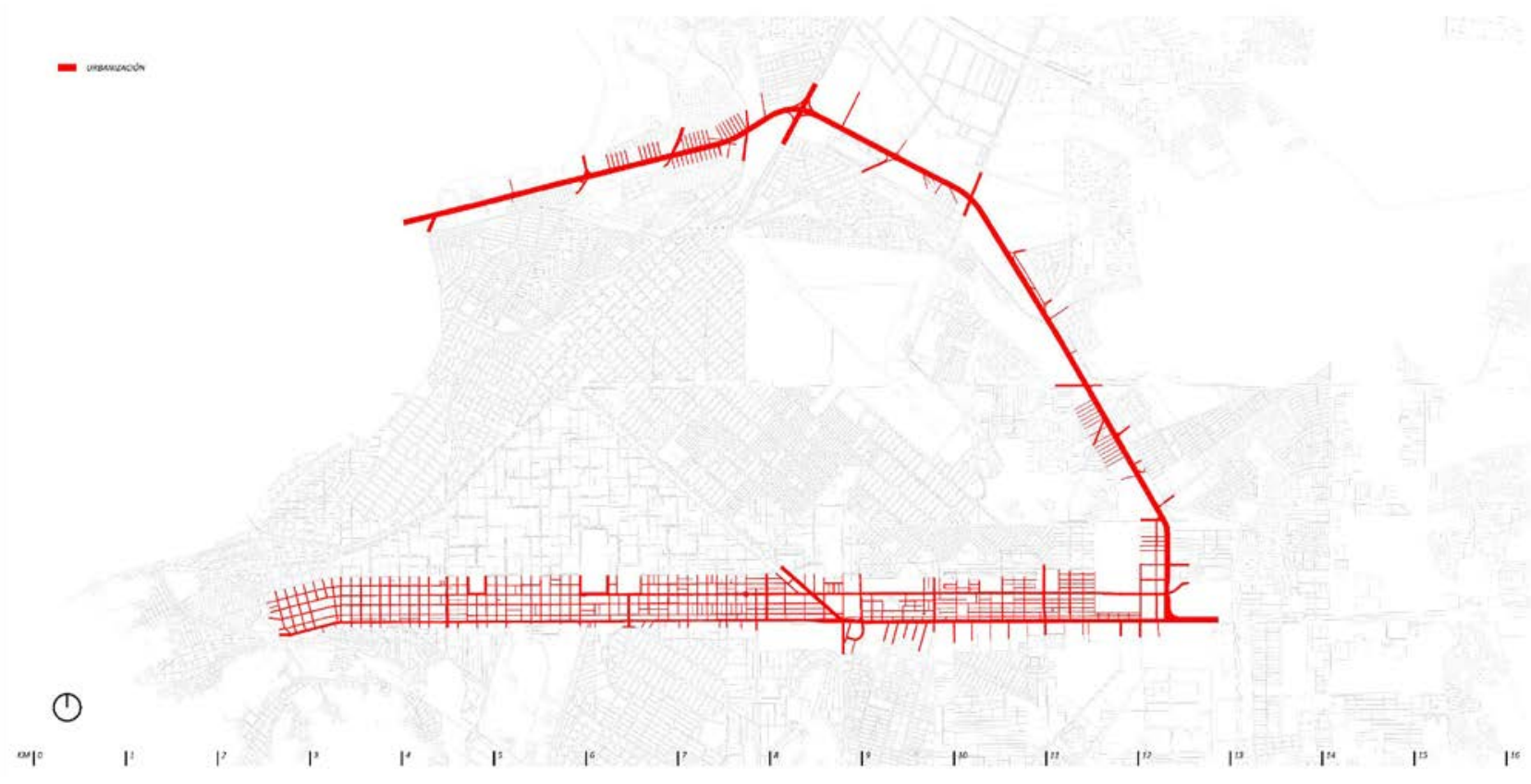

Fig. 6 Tramas y tejidos en zona de estudio. Elaboración propia a partir de cartografía urbana

La trama y el tejido urbano es aquella malla que se genera y forma un borde hasta el cual podrá llegar la parcela. Esta malla puede influir significativamente en el contacto casual y fortuito que pudiera suceder entre las personas. La disminución de éste contacto puede resultar en una impersonalización con el territorio y por lo tanto en una dificultad de adopción de vínculo de identidad.

Si la medida entre cruces de la malla es corta se puede abrir posibilidad a la repetida intersección de movimiento y actividad, se crean rutas alternativas que rompen el paseo estéril. Por el contrario, si la medida entre cruces es demasiado grande, el movimiento y la actividad pierden permeabilidad. Se disipa la diversidad en el contacto casual que genera a su vez la apropiación del espacio y la adopción de identidad. Esta reflexión se basa en la teoría de Jane Jacobs y su discurso sobre los bloques cortos. Fig. 7

\subsubsection{La continuidad de la trama frente a los contactos dispersos}

En el caso del centro tradicional la trama y el tejido se divide en una retícula con mayor cantidad de cruces donde los espacios entre las intersecciones se encuentran en un rango de 90 a 200 metros de separación. En cambio, en la centralidad periférica, la retícula es mucho más dispersa. En el periférico existen separaciones entre las intersecciones que varían de los 50 hasta los 900 metros aproximadamente.

Esta trama de calles define aspectos de la identidad ya que las actividades realizadas por los actores de la ciudad pueden ser con permeabilidad en el centro tradicional y con impermeabilidad en la centralidad periférica. 


\subsection{La identidad en la proximidad o en un nuevo sistema de parques}

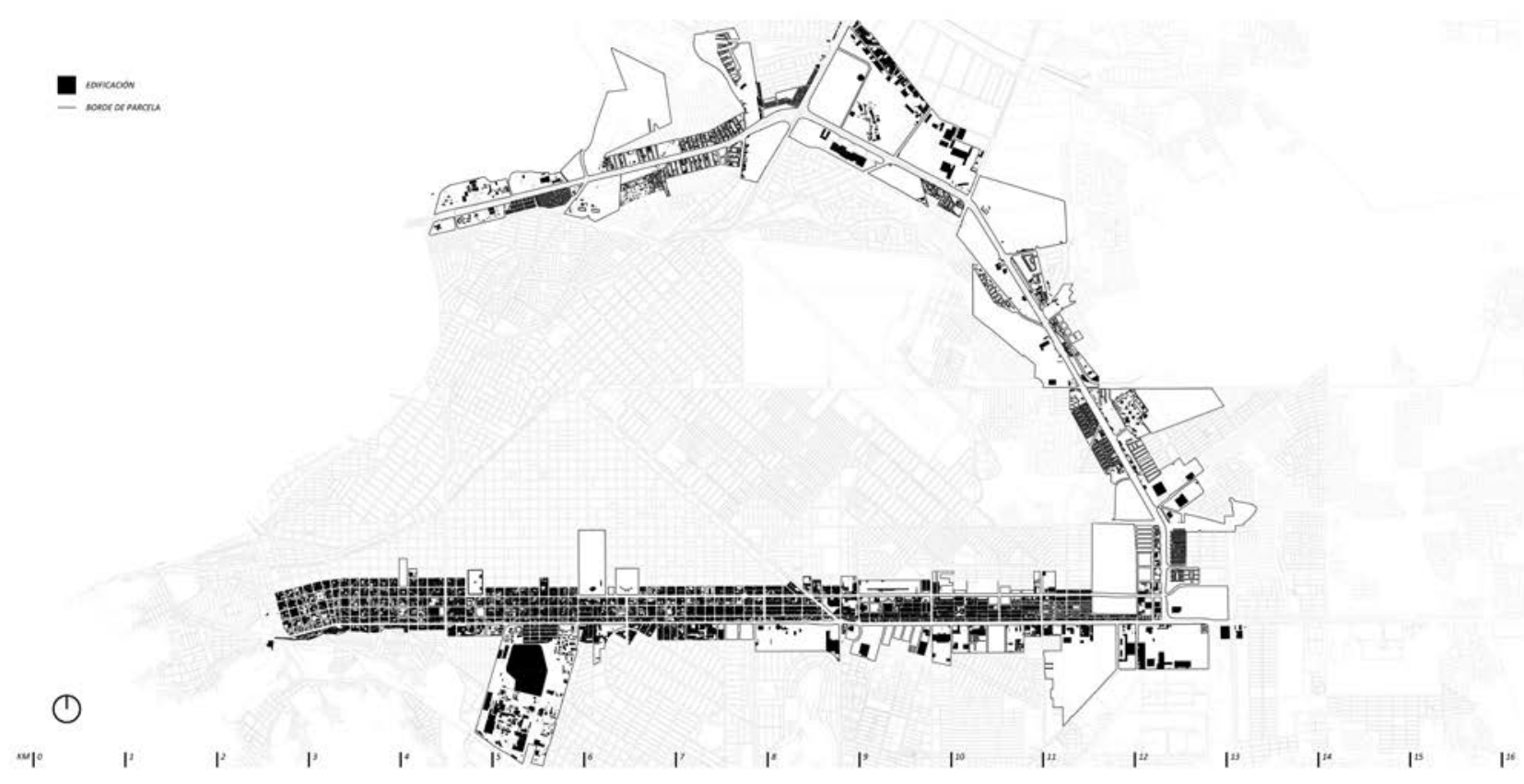

Fig. 7 Parcela, edificación y espacio abierto. Elaboración propia a partir de cartografía urbana

En Torreón la centralidad periférica muestra predominación en parcelas de gran dimensión. Estas parcelas pueden llegar a tener la dimensión de 65 hectáreas mientras que la centralidad tradicional muestra en su mayoría parcelas en dimensiones aproximadas a media hectárea.

En cuanto a la edificación podemos observar una solidificación de elementos en el centro tradicional los cuales se disponen con la cercanía de estar en contacto directo entre ellos. Por otra parte, en la centralidad periférica observamos elementos de edificación aislados y dispersos en el territorio.

Si sobreponemos las parcelas junto a los edificios obtenemos una visual de lo que representa el espacio abierto. Por un lado la centralidad tradicional muestra poco espacio abierto mientras que la centralidad periférica nos muestra gran cantidad de espacio abierto.

La centralidad periférica será más propensa a otros tipos de oportunidad. El tipo de oportunidad será en la búsqueda de actividades extensas con grandes dimensiones y recorridos internos en las parcelas. Por mencionar un ejemplo, este sitio abierto podrá generar la creación de un espacio tipo system park, que no necesariamente por ser un espacio abierto sea antagonista de la identidad. Las extensiones verdes o paseos arborizados puede repensarse y replantearse; significando higiene y libertad y no aglutinamiento social y marginal de los habitantes.

El centro tradicional por el contrario es un espacio más compacto que el centro periférico, donde se debería buscar la cercanía entre elementos para aportar una mezcla de usos y niveles sociales para prevenir la formación de la vida social agresiva.

En base a ello y haciendo alusión a este trabajo, queda pensar en aquellos espacios urbanos que tienen gran dimensión de espacio vacío y que son propensos a generar libertad. En este caso el espacio vacío del periférico aun es de alguna manera virgen y se resiste a la consolidación de los guetos sociales. Puede plantearse y reinterpretarse para generar aquello que mejore su habitabilidad. 
4.3 Del espacio de los flujos a la transversalidad peatonal: el velocímetro de la identidad

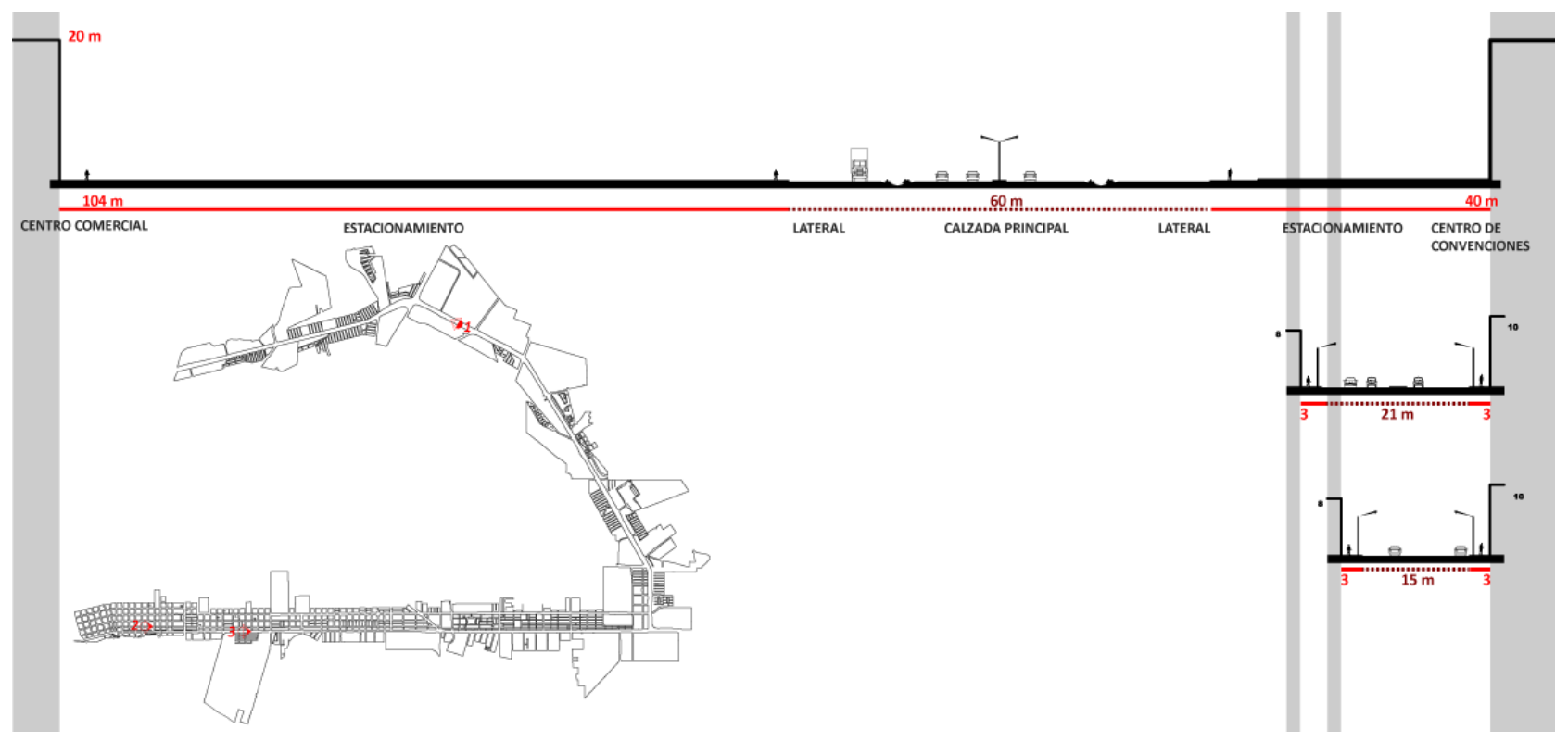

Fig. 8 Sección de calle de la centralidad periférica y la centralidad tradicional. Elaboración propia a partir de cartografía urbana

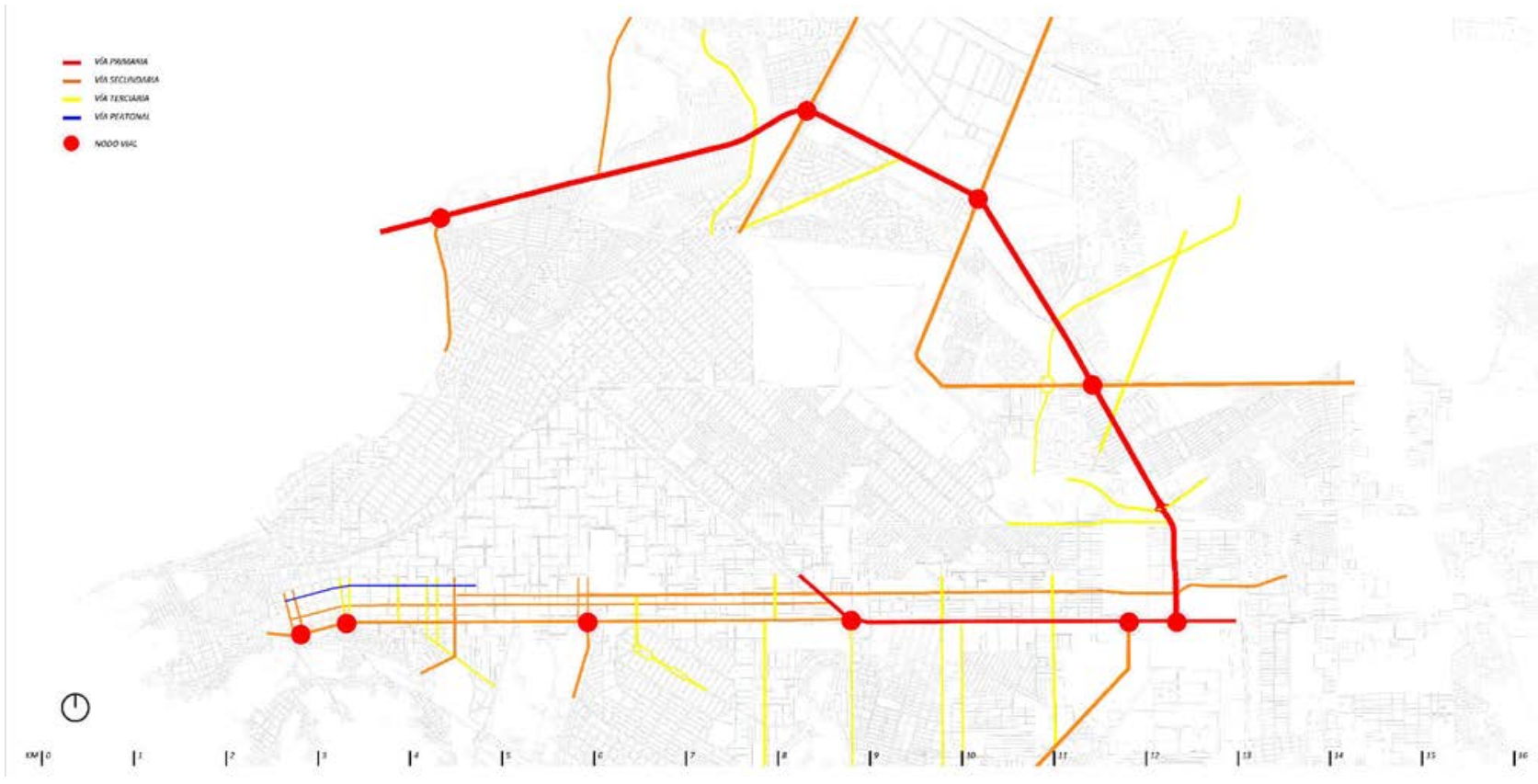

Fig. 4 Vías y nodos urbanos Elaboración propia a partir de cartografía urbana e IMPLAN

Aunque en su origen no fue un destripamiento, el periférico Raúl López Sánchez al ser una vía rápida y con un vacío entre edificios de hasta doscientos metros, actúa como frontera donde se degradan sus bordes y no favorece los flujos peatonales transversales. En vida y muerte de las Grandes Ciudades encontramos una definición que se asemeja a la de esta vía:

"Centros cívicos que sólo frecuentan los indigentes, los que no pueden elegir sus lugares de esparcimiento. Centros comerciales que son una imitación sin lustre de los de las avenidas comerciales al uso, plagadas de franquicias. Paseos que van de ningún sitio a ninguna parte y que no tienen paseantes. Vías rápidas que destripan las grandes ciudades... Esto no es reordenar las ciudades. Esto es saquearlas" (Jacobs:1963, 24)

En la centralidad tradicional se observa otro fenómeno, con una callis (distancia interesante entre edificios) de cotas muy generalizables que en promedio alcanzan los 25 metros, permiten desde contactos visuales, la 
proximidad entre edificios y actividades, y así podemos observar como la transversalidad tanto del tráfico rodado como del peatonal hacen de la vía un linde más que una frontera.

Las vías y los nodos predominantes nos muestran las conexiones estructurantes y la permeabilidad transversal para la movilidad. La centralidad periférica es la arteria de movimiento que con cinco nodos permiten los cambios de dirección pero no precisamente de intercambio. La otra zona de estudio, emplaza cinco nodos de los cuales los tres en dirección oriente-poniente, manifiestan la segunda condición de ser puntos de reunión para la gente; podemos notar que la transversalidad de las vías secundarias y terciarias se intensifica, también se encuentra una calle peatonalizada en sentido paralelo al eje vial sobre el que cuelga la centralidad histórica.

La centralidad periférica es de un carácter más parecido al de una autopista: sobrestima la vía primaria y se segrega de las vías secundarias, imposibilitando los recorridos peatonales tanto transversales como longitudinales, y donde la interacción corre a cargo del vehículo motorizado.

\subsection{Perspectiva panorámica como morfología implicita}

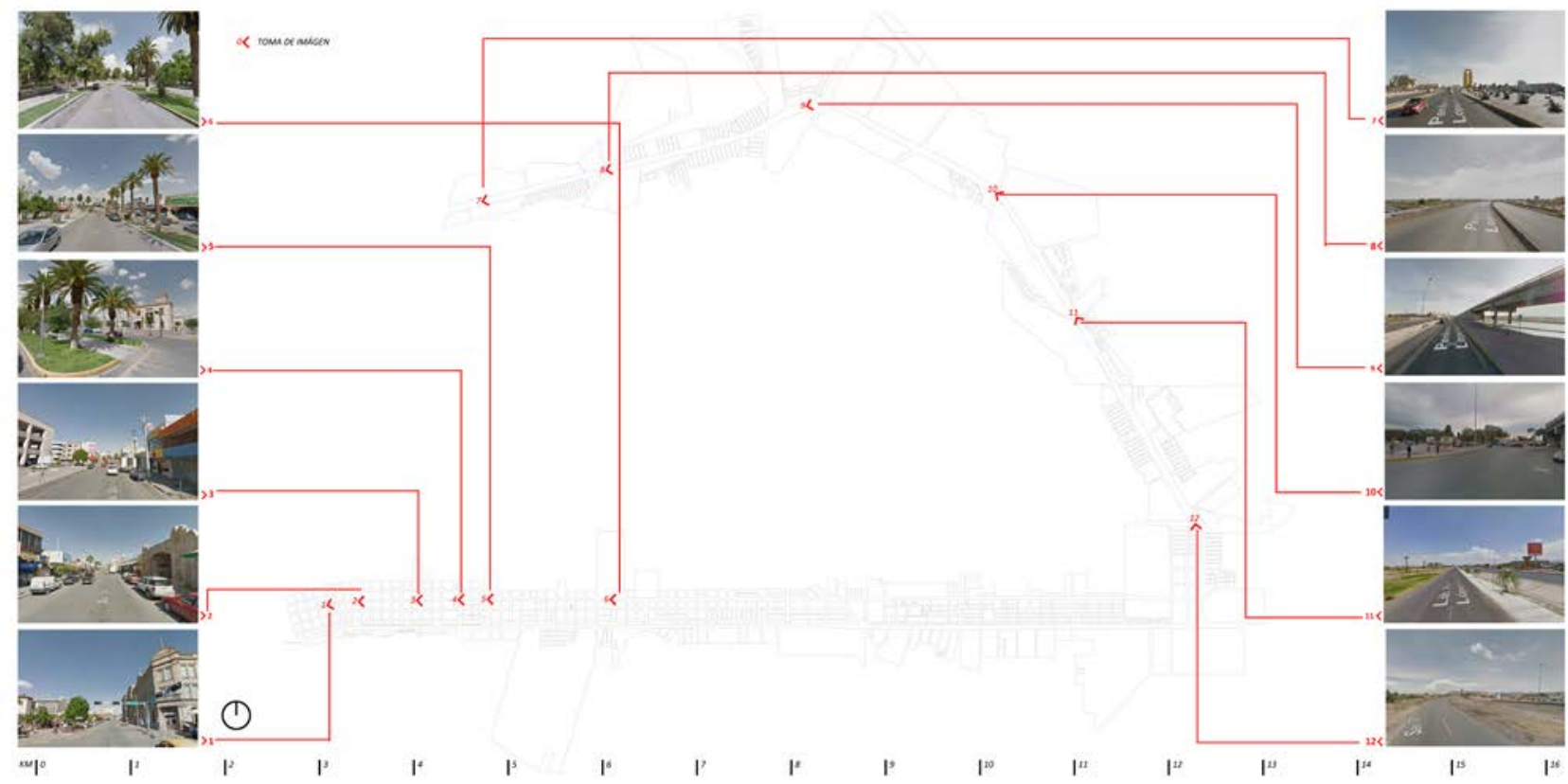

Fig. 10 Perspectivas panorámicas en distintos puntos del área de estudio Elaboración propia a partir de cartografía urbana y Google maps

La morfología urbana de la ciudad de Torreón se observa de manera implícita desde sus perspectivas panorámicas. La forma del espacio urbano se clasifica en dos visiones: amplia en la centralidad periférica y estrecha en la centralidad tradicional. Estas líneas de movimiento además sugieren unas visuales relevantes. Estas visuales nos crean una imagen urbana identitaria. Estas líneas de movilidad nos hacen observar constantemente ciertos objetos que quedan en nuestra memoria. Estos recuerdos nos dan un significado sobre lo que la sociedad representa.

"El derecho a la centralidad accesible y simbólica, a sentirse orgullosos del lugar en el que se vive y a ser reconocidos por los otros, a la visibilidad y a la identidad, además el disponer de equipamientos y espacios públicos cercanos, es una condición de ciudadanía. También es un derecho de ciudadanía el de la movilidad, ya que supone información e intercambio, oportunidades de formación y de ocupación, posibilidades de acceder a las ofertas urbanas y apropiarse de la ciudad como un conjunto de libertades. Si los derechos de centralidad y de movilidad no son universales, la ciudad no es democrática." (Jordi Borja y Zaida Muxi p.15)

Este radio visual amplio en la centralidad periférica, posibilita la circulación a alta velocidad y la distancia entre la calzada vehicular y la edificación permiten al conductor anticiparse a cualquier obstáculo. Entonces, la relación entre la perspectiva visual y la velocidad de los flujos es inversamente proporcional a los contactos imprevistos o a las actividades resultantes tal como lo definió Jan Gehl. La panorámica periférica nos sugiere 
una dilatación del espacio y libertad de movimiento que podrá ser útil para actividades de paso y conexión entre elementos a larga distancia, más por el contrario no sugiere una situación de estancia o paseo.

Por otra parte la centralidad tradicional nos sugiere unos espacios estrechos. Estos espacios podrán regenerarse y adaptarse a nuevas necesidades siempre y cuando cumplan con restricciones prestablecidas anteriormente por la morfología urbana. El centro tradicional se encuentra hermanado a la escala peatonal. Debido a la proximidad de la edificación que se observa en su panorámica se imposibilita la circulación a alta velocidad, ya que no es posible visualizar elementos en movimiento a corta distancia. En este espacio tradicional el contacto visual entre los peatones se puede dar de manera fortuita.

\section{LA ESTRUCTURA URBANA - EL SOPORTE DE IDENTIDAD}

\subsection{El uso del suelo tradicional y periférico - lo mixto como próximo y lo monótono como lejano}

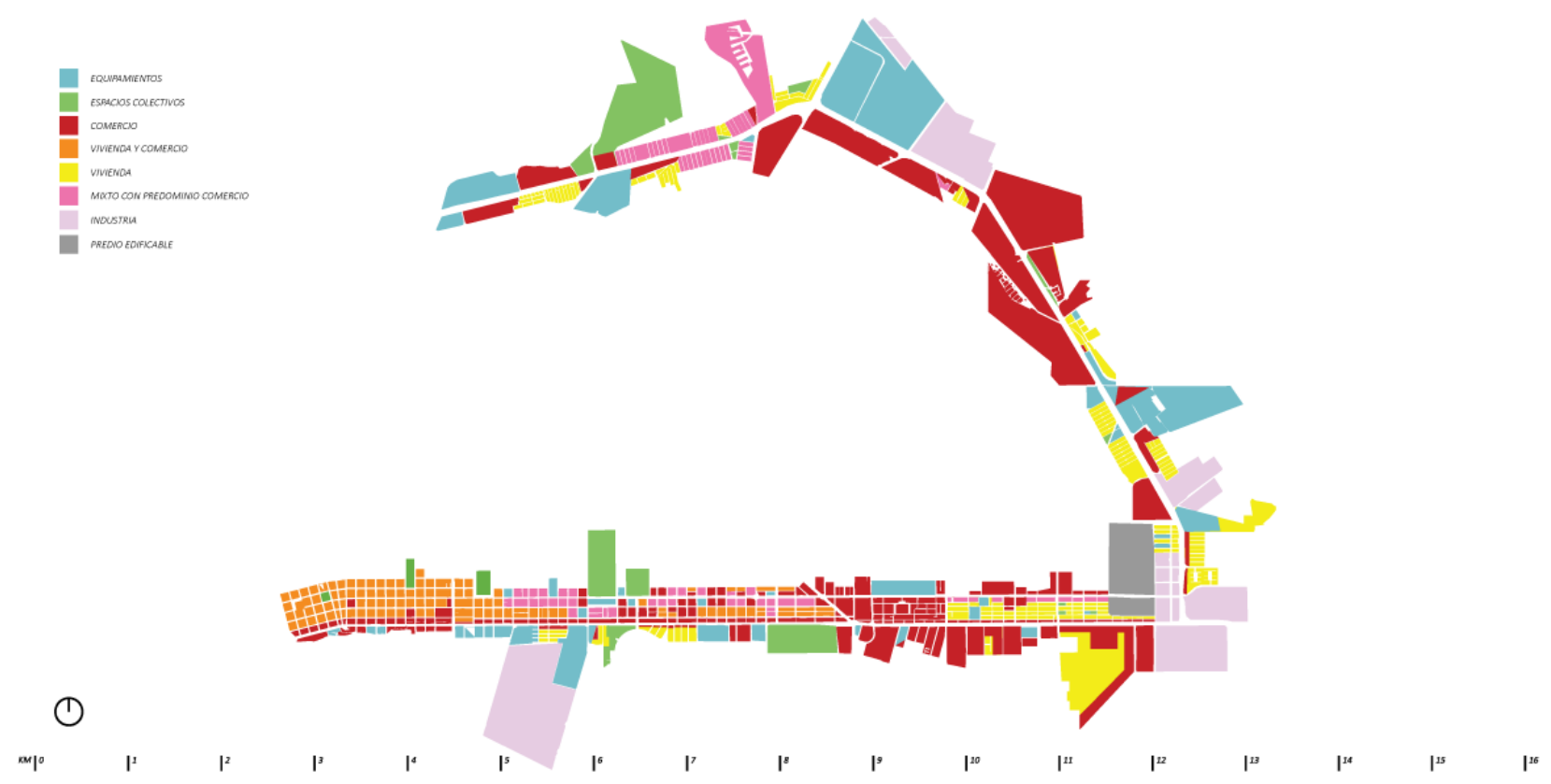

Fig. 11 Uso de suelo secundario en área de estudio Elaboración propia a partir de IMPLAN

El uso de suelo acota la diversidad de actividades que pueden suceder en el espacio urbano. La mezcla de usos genera espacios vivos la mayor parte del día, así se confirma lo que Jane Jacobs observó y expuso en la muerte y vida de las grandes ciudades. Por otra parte, se puede hacer alusión a las ideas de Jordi Borja y Zaida Muxi:.

"Sin duda, la deformación del urbanismo funcionalista combinando zonificación y privatización es la caricatura perversa del movimiento moderno, crea una nueva imagen de la "ciudad emergente" en la que las piezas, los "productos", la arquitectura de los objetos - mercadería, sustituyen la ciudad del intercambio y de la diversidad. La ciudad fragmentada tiene tendencia a ser una ciudad físicamente despilfarradora, socialmente segregada, económicamente poco productiva, culturalmente miserable y políticamente ingobernable. Es la negación de la ciudad, que en la práctica niega el potencial de las libertades urbanas, la promesa de justicia y los valores democráticos." (Jordi Borja y Zaida Muxi p.15)

La centralidad periférica de Torreón debería ser el lugar del intercambio cultural con la región y diversidad, para dejar de ser un eje que en su mayoría contiene los espacios colectivos para la actividad comercial.

Si observamos el uso de suelo secundario (definido en parcelas por el ayuntamiento de Torreón) podremos notar que en la zona periférica se crean "islas" de monotonía mientras que en la centralidad tradicional existe mayor cantidad de espacios con condiciones para la convivencia de usos mixtos. Se concluye que de combinar el uso de suelo con el plano de flujos y nodos, no existe una relación que apareje la convergencia de sendas con el foco donde se reúne la gente. Las oportunidades de contacto son un tema relevante para la identidad y se multiplican por la mixtura funcional, tal como lo han dicho antes: 
"Si la diversidad y el intercambio son dimensiones fundamentales, la "ciudad ciudad" es aquella que optimiza las oportunidades de contacto, la que apuesta por la diferenciación y la mixtura funcional y social, la que multiplica los espacios de encuentro." (Jordi Borja y Zaida Muxi p.16)

\subsection{La dicotomía entre la población y la oferta de transporte público: una estrategia para romper la monotonía}

La velocidad de proyecto en la centralidad periférica oscila entre 70 y $100 \mathrm{~km} / \mathrm{h}$, mientras que para la centralidad tradicional es de $20-60 \mathrm{~km} / \mathrm{h}$. Usando las conclusiones del estudio de Jan Gehl sobre tres vías en San Francisco, donde las distintas velocidades de movimiento son un parámetro definitorio, podemos concluir para Torreón que las rutas de transporte público tampoco favorecen la transversalidad ni penetran en las islas de usos del periférico; entonces se mantiene la idea de los flujos donde a mayor velocidad de movimiento menor relación entre las personas y menor identificación entre los residentes.

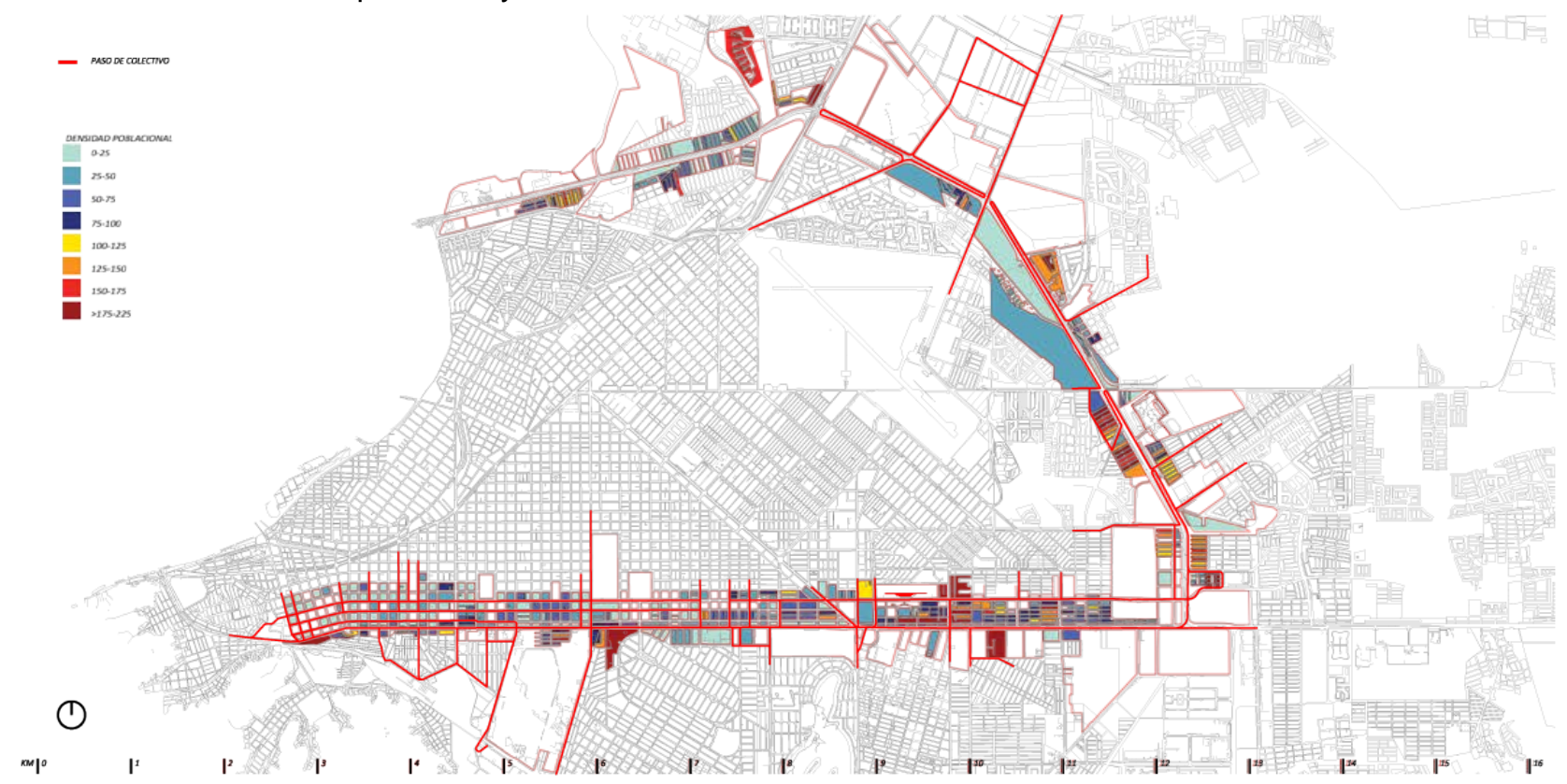

Fig. 12 Paso de autobús colectivo en superposición a densidad poblacional Elaboración propia a partir de IMPLAN e INEGI

En la ciudad de Torreón las formas de desplazamiento se basan un 2\% en bicicletas, 19\% en peatones, 30\% en transporte público (autobús colectivo) y $49 \%$ en vehículo privado. En base al dibujo anterior queda en evidencia que la base del movimiento de personas se apoya en el transporte privado. Siendo así, surge la necesidad de restructurar el transporte colectivo pues resulta inviable pensar que las manifestaciones sociales se puedan apoyar en él, cuando para la centralidad histórica que es la que tiene menor población el sistema es muy robusto; pero para el periférico la línea del colectivo no recorre toda la traza de la vía y menos se adentra por entre el tejido que cuelga de dicho elemento infraestructural. 


\subsection{El patrimonio en bajo contacto habitacional}

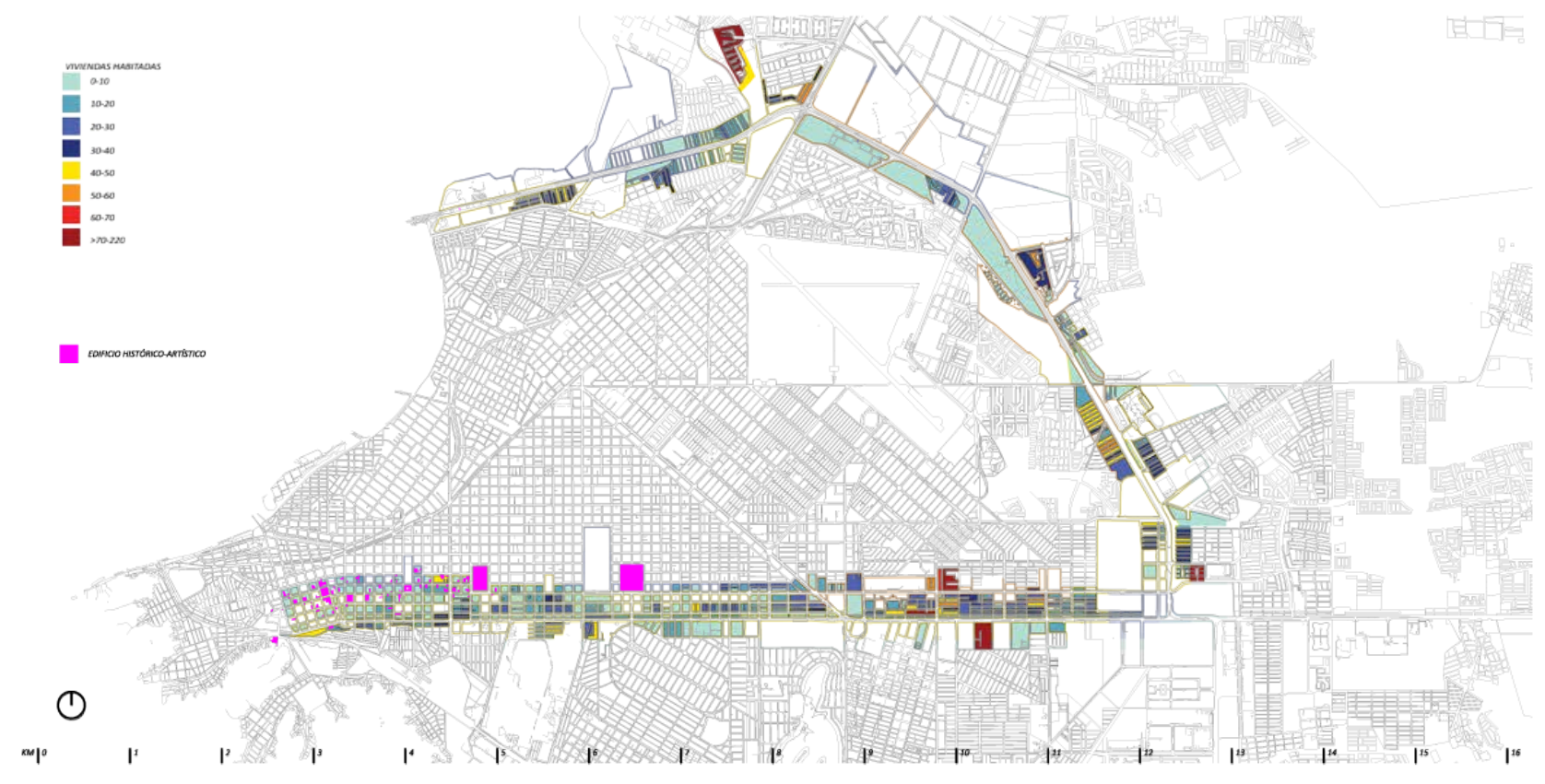

Fig. 13 Localización de edificios patrimoniales en superposición a la vivienda habitada Elaboración propia a partir de IMPLAN e INEGI

El patrimonio histórico-artístico de la ciudad de Torreón aunque se encuentra catalogado, ha visto muchas veces modificado, en algunos casos, mediantes su preservación y en algunos otros mediante su destrucción. Del artículo El valor estructurante del patrimonio en la transformación del territorio por Joaquín Sabaté y Julián Galindo podemos entender que el valor del paisaje se puede encontrar como patrimonio cultural e histórico, pues es necesario:

“...entender que el paisaje y el territorio son una realidad en continua evolución, como la sociedad que los crea, y que aquello que debe preocuparnos no es tanto asegurar su inmutabilidad basándonos en la protección-, sino evitar que, en el natural proceso de transformación, el territorio y el paisaje se vean despojados de sus valores patrimoniales, simbólicos, en definitiva, de su identidad. Por tanto, sin el reconocimiento y la defensa de los valores del paisaje, no es posible la gestión del territorio en beneficio de la colectividad. Por ello, el patrimonio, la identidad del territorio, debe convertirse en un factor más en la ordenación territorial." (Joaquin Sabaté y Julián Galindo p.23)

La mayoría de las reliquias que conforman el patrimonio cultural de Torreón, se contienen entre la trama más fundacional de la ciudad casi junto a la antigua estación de ferrocarril, ámbito que además, presenta los índices más altos de vivienda abandonada de la ciudad. Esta investigación se aventura al decir que seguramente las restricciones que imponen las disposiciones legales sobre los bienes catalogados como patrimoniales, no permiten las modificaciones necesarias para actualizar esas fincas con más de cien años a las condiciones necesarias de habitabilidad del tiempo contemporáneo; siendo así es difícil pensar que aunque la trama histórica es la que más propicia los contactos fortuitos entre las personas y la construcción de una identidad, los torreonenses se atrevan a vivir en condiciones precarias o en espacios no actualizados. 


\section{EL COMPORTAMIENTO SOCIAL - MANIFESTACIÓN DE IDENTIDAD EN LA CENTRALIDAD TRADICIONAL Y PERIFÉRICA}

\subsection{Una ciudad, dos imágenes urbanas}

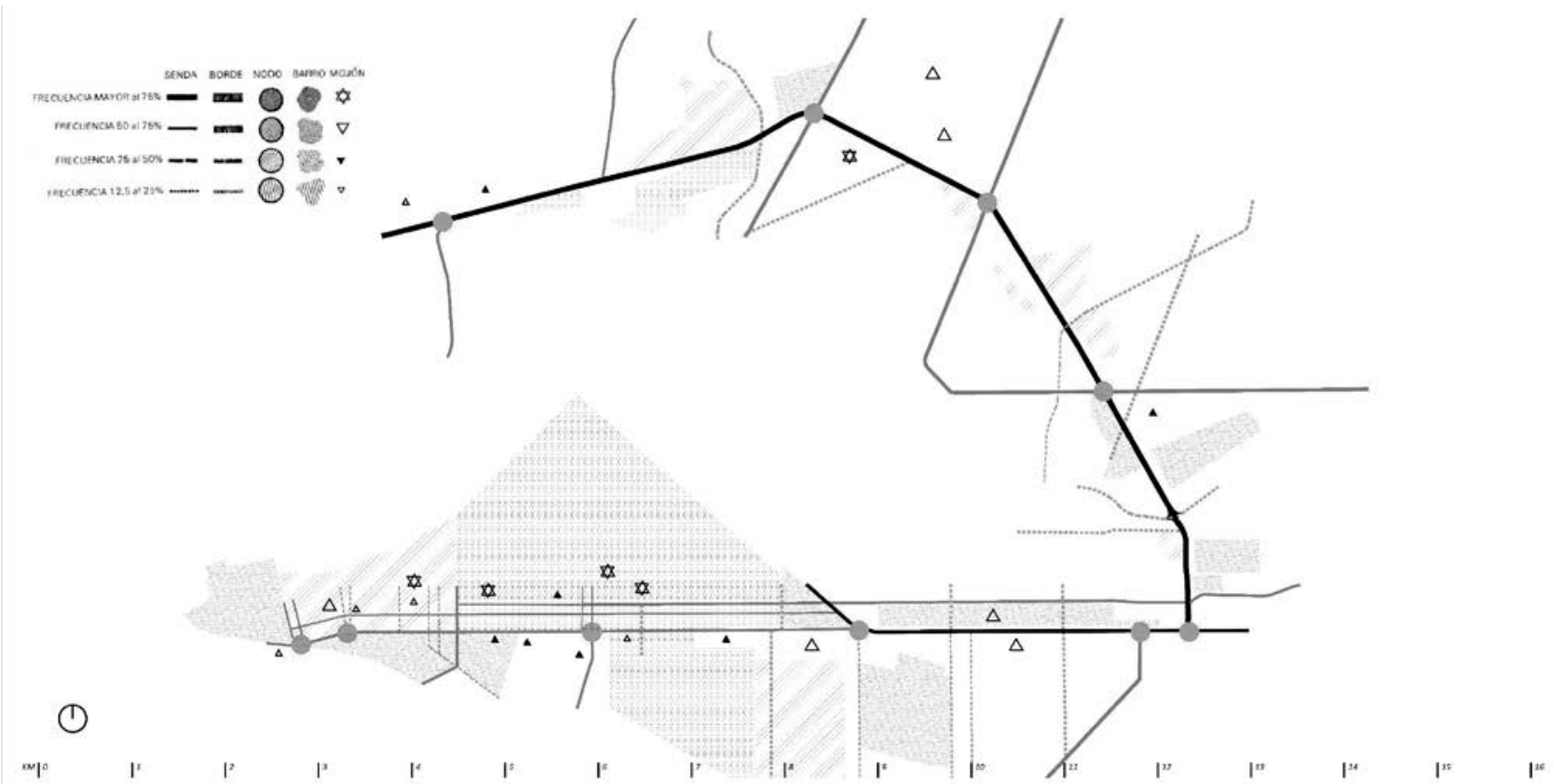

Fig. 14 Dibujo sobre la imagen de la ciudad de Torreón haciendo alusión a la teoría de Kevin Lynch Elaboración propia a partir de cartografía urbana

Del libro La imagen de la ciudad escrito por Kevin Lynch podemos identificar los cinco elementos que conforman las dos imágenes de Torreón: sendas, nodos, bordes, barrios y mojones. En los barrios tradicionales pueden llegar a confundirse entre sus límites pues la trama permite los flujos transversales y longitudinales. Está cargada de hitos o mojones que marcan el territorio y la jerarquía de sendas provoca un sistema igualitario entre las vías primarias, secundarias y terciarias lo que crea una imagen de ciudad para la escala humana.

La otra imagen que cuelga del periférico es la de una senda que conduce los flujos metropolitanos y que por su sección y la falta de elementos edificados en proporción a esa envergadura, se convierte en un borde para el territorio. Se observa también como los hitos se convierten en elementos muy dispersos y donde casi pierden la relación con la vía; al contrario del centro tradicional los barrios si encuentran límites definidos.

Es necesario mencionar que no calificamos de mejor o peor ambas imágenes, pues la zona histórica lucha por conservar una identidad producto de su fundación y la otra, por construirse una imagen que mide al futuro y a la región metropolitana de La Laguna, por ello es bueno recordar que:

"La imagen es fundamental, y para reforzar la de cada lugar es preciso reconocer su identidad y destacarla. Muchas de nuestras valoraciones se basan en percepciones. De ahí la importancia de un icono o de un logo. Nos permiten referir cada rincón, cada uno de los recursos, a una escala superior; encontrar elementos identificativos, que nos remitan constantemente al conjunto." (Sabaté, De la preservación del patrimonio a la ordenación del paisaje p.24) 


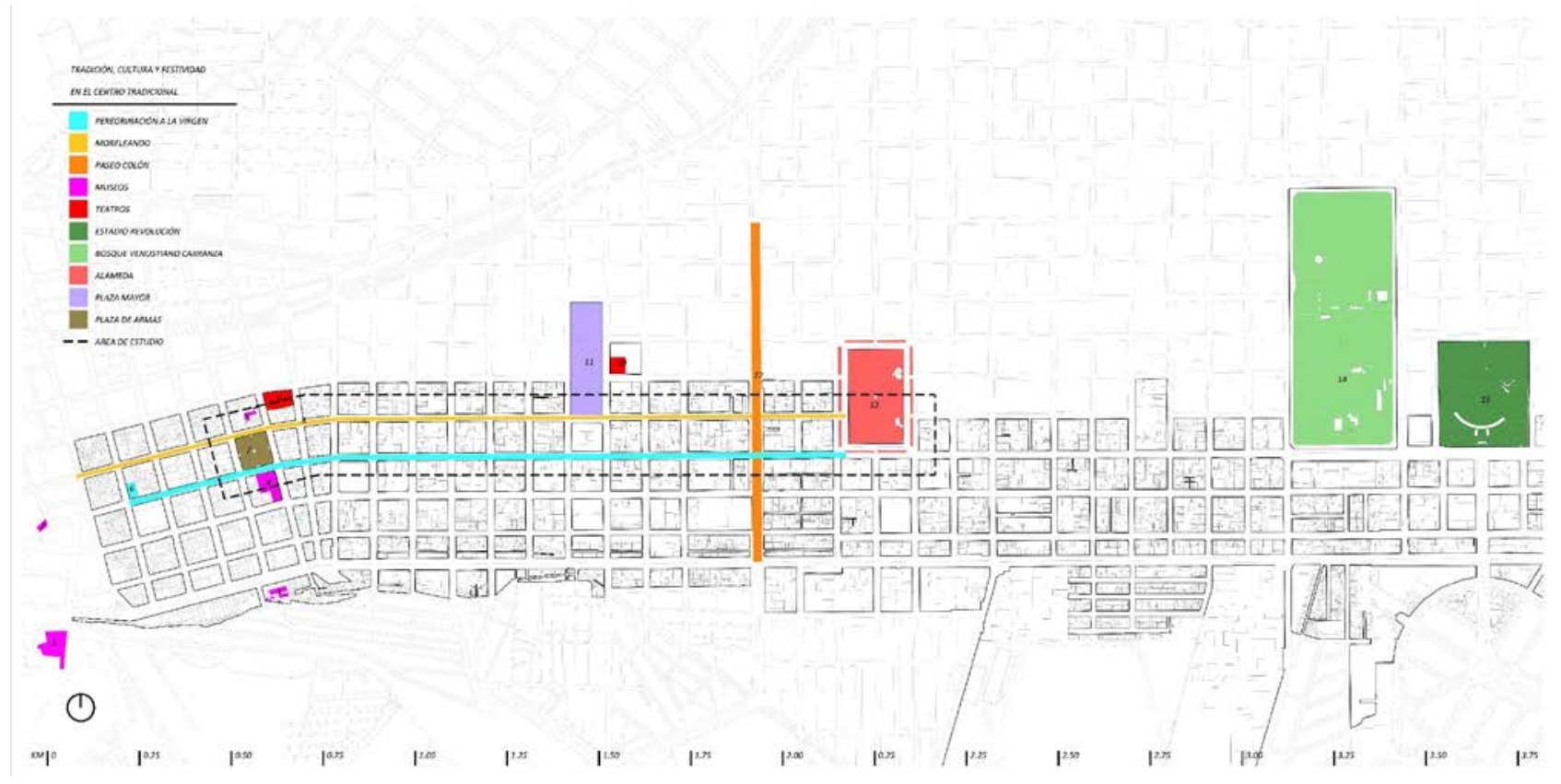

Fig. 15 Localización de los elementos de tradición, cultura y festividad en el centro tradicional Elaboración propia a partir de cartografía urbana

La tercera hipótesis se verifica cuando la mayoría de manifestaciones culturales y de nuevas tradiciones se viven dentro de la trama compacta del centro tradicional. Se observan tres eventos que se desarrollan sobre las calles, pero no ha habido un proyecto urbano que convierta los eventos puntuales en situaciones cotidianas, que a su vez refuercen la noción completa de identidad.

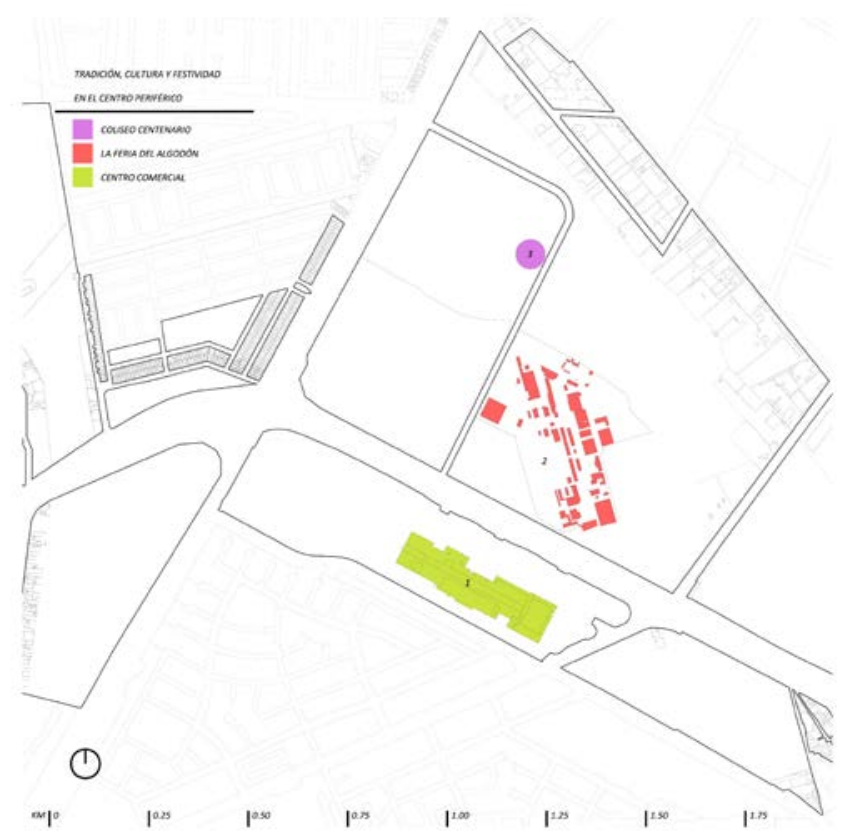

Fig. 16 Localización de los elementos de tradición, cultura y festividad en la centralidad periférica Elaboración propia a partir de cartografía urbana 


\section{Conclusiones}

Por medio de las condiciones de forma y estructura podemos afirmar que la velocidad a la cual circulan las personas en cada una de estas áreas de centralidad es muy distinta, más peatonal en la ciudad histórica lo que permite las manifestaciones tradicionales, la transversalidad peatonal y el transporte público y en general los usos mixtos. La centralidad periférica al ser más veloz al ser una vía de tránsito rápido y que soporta los grandes equipamientos y los nodos de servicios comerciales, diluye los contactos fortuitos y concentra las actividades y los usos en parcelas de gran dimensión.

Las dinámicas de población en Torreón producen un doble efecto en su sistema de centralidades: un deterioro en la imagen del centro tradicional que se resiste a olvidar sus tradiciones pero que empieza a incorporar nuevas dinámicas de apropiación del espacio urbano; una oportunidad en la centralidad periférica para convertirla en un elemento infraestructural de escala metropolitana que soporte los flujos del transporte público y que complemente los usos que el centro tradicional no puede ofrecer.

\section{Bibliografía}

Archivo Municipal. Torreón, s.f.

Guerra, Eduardo. Historia de Torreón su Origen y sus Fundadores. Torreón: Ayuntamiento de Torreón, 1932.

Cuadros, Carlos Castañón. Fraccionamientos de Cobián. Entre la historia y el presente. Torreón: Editorial La Opinión, S. A., 2014.

Favela, Luis Carlos Herrera. Anatomía de la Memoria. El patrimonio construido en el Conjunto Histórico de Torreón. Torreón: Buenaval, 2009.

Flores, Juan Gramillo. Torreón ciudad centenaria, antecedentes, fundación y desarrollo. Torreón: Editorial La Opinión. S. A., 2006.

Moreira, Rubén. PLAN Director de Desarrollo Urbano del Municipio de Torreón, Coahuila. Saltillo, 2014.

PROGRAMA ESTATAL DE DESARROLLO URBANO Y ORDENAMIENTO TERRITORIAL DE COAHUILA DE ZARAGOZA 2011-2017. Coahuila, México: Gobierno del Estado de Coahuila, 2011.

Calhoun, John C. «La construcción de la identidad.» Castells, Manuel. La era de la información - Economía, sociedad y cultura. El poder de la Identidad Vol 2. Mexico: Siglo XXI editores S.A. de C.V., 1997. 28.

Castells, Manuel. La era de la información: Economía, sociedad y cultura. El poder de la identidad Vol.2. Mexico: Siglo XXI editores S.A. de C.V., 1997.

Jacobs, Jane. Muerte y vida de las grandes ciudades. Nueva York: epublibre, 1961.

Jordi Borja y Zaida Muxi. El espacio público, ciudad y ciudadanía. Barcelona, 2000.

Koolhas, Rem. La ciudad Genérica. Barcelona: Gustavo Gili, 1994.

Lynch, Kevin. La Buena Forma de la ciudad. Bacelona: Gustavo Gili, 1985.

- La imagen de la ciudad. Barcelona: Gustavo Gili, 1998.

Sabaté, Joaquín. De la preservación del patrimonio a la ordenación del paisaje. Universidad Politécnica de Catalunya, s.f.

Sabaté, Joaquín. «De la preservación del Patrimonio a la Ordenación del Paisaje: Intervenciones en Paisajes Culturales en Latinoamérica.» Paisajes Culturales: Comprensión, protección y gestión. Madrid: Dirección General de Relaciones Culturales y Científicas, 2010. 11-23.

Joaquin Sabaté y Julián Galindo. «El valor estructurante del patrimonio en la transformación del territorio.» APUNTES (2009): 23. pdf.

\section{Fuentes electrónicas}

Anónimo. Algo de aquí, algo de allá. 17 de 03 de 2013. $<$ https://algodeaquialgodealla.wordpress.com/2013/03/17/conociendo-el-antiguotorreon/\#comments>.

García, Victor. Conquistador del Tiempo. 29 de 04 de 2014. <https://conquistadordeltiempo.blogspot.com.es/2014/04/foto-de-la-historica-presa-del-coyote.html>. Hispavista, Galeón. Estación Torreón. 2017. <http://estaciontorreon.galeon.com/productos627865.html>. Instituto Nacional de Estadística y Geografía. 12 de 12 de 2015. <http://buscador.inegi.org.mx/>. Joaquín Lopez Dóriga. 13 de 10 de 2015. <http://lopezdoriga.com/nacional/hombre-es-baleado-en-torreon/>. Morrison, Allen. Los Tranvías de Lerdo, Gomez Palacio y Torreón. 2003. $<$ http://dacomedores.tripod.com/lerdo/>. 
NASA. http://www.datacenterdynamics.com. 02 de 10 de 2015.

Olivares, Javier. Torreón en sus Buenos Tiempos. 24 de 10 de 2016. $<$ https://www.facebook.com/photo.php?fbid=10207272659206885\&set=g.221286794584077\&type= 1\&theater>.

Rico, Ilhuicamina. Batallas en el Desierto. 6 de 12 de 2010. <https://batallaseneldesiertoilhuicamina.blogspot.com.es/2010/12/cronologia-de-torreon-1847-1900.html>.

Rodríguez, Dr. Leonel. El Siglo de Torreón. 4 de 03 de 2007. $<$ https://www.elsiglodetorreon.com.mx/noticia/266498.historia-de-la-construccion-del-torreon.html>.

Saludado, Teresita Benites. IMPLAN Torreón. 26 de 05 de 2015. <http://www.trcimplan.gob.mx/blog/zonametropolitana-laguna.html>.

Schott, Cecilio Secunza. Milenio Laguna. 18 de 12 de 2016. $<$ http://www.milenio.com/region/IMPLAN_Torreon-

Estructura_y_traza_urbana_de_Torreon_0_671332911.html>.

Solís, Miguel Angel Riquelme. «Plan Desarrollo Urbano.» 2014. Plan Municipal de Desarrollo 2014-2017. <http://www.torreon.gob.mx/pdf/PMD_Torre\%C3\%B3n.pdf>.

Torreón, Archivo Municipal

de.

Acervos

Documentales.

s.f. $<$ https://acervosdocumentalestorreon.blogspot.com.es/p/planos-de-la-ciudad-de-torreon-coah.html>.

Torreón, IMPLAN. Plan Estratégico Metropolitano de La Laguna. Saltillo, 01 de 12 de 2015. 